DOI 10.37882/2223-2982.2021.04.04

\title{
ФОРМИРОВАНИЕ КУЛЬТУРЫ ДЕЛОВОГО ОБЩЕНИЯ В ПРОФЕССИОНАЛЬНОЙ СФЕРЕ У СТУДЕНТОВ НЕЯЗЫКОВОГО АГРАРНОГО ВУЗА
}

\section{FORMATION OF A CULTURE OF BUSINESS COMMUNICATION IN THE PROFESSIONAL SPHERE AMONG STUDENTS OF A NON- LINGUISTIC AGRICULTURAL UNIVERSITY \\ Yu. Bogdanova}

Summary: The article is devoted to one of the most pressing problems in higher school pedagogy. The author conducted a monitoring of the formation of a business communication culture among students of a nonlinguistic agricultural university. Based on the research, he developed and implemented in the pedagogical process of the university an adapted method of forming a culture of business communication in the professional sphere, which ultimately gave a positive result and showed effectiveness.

Keywords: monitoring, culture of business communication, specifics of business communication, problem situations.

\author{
Богданова Юлия Зуфаровна \\ К.филол.н., дочент, Государственный аграрный \\ университет Северного Зауралья, Тюмень \\ bogdanowa2907@mail.ru
}

Аннотация: Статья посвящена одной из актуальных проблем в педагогике высшей школы. Автор провел мониторинг сформированности культуры делового общения у студентов неязыкового аграрного вуза. На основе проведенного исследования им была разработана и внедрена в педагогический процесс вуза адаптированная методика формирования культуры делового общения в профессиональной сфере, которая в конечном итоге дала положительный результат и показала эффективность.

Ключевые слова: мониторинг, культура делового общения, специфика делового общения, проблемные ситуации.
$\mathrm{B}$ настоящее время сложились такие рыночные отношения в сфере труда, когда востребованность специалиста на рынке труда, его конкурентоспособность в значительной степени зависят от культуры делового общения, от знания приемов речевого воздействия, убеждения и т.д. [5].

Дисциплина «Культура речи и деловое общение» относится к циклу ФГОС Высшего профессионального образования. Наряду с другими дисциплинами гуманитарного цикла она является составной частью гуманитарной подготовки студентов и первым этапом их обучения культуре делового общения в профессиональной сфере. Современный специалист обязан уметь устанавливать деловые отношения, вести деловые переговоры, быть функционально грамотным в обращении с деловой документацией [9].

Формирование культуры делового общения, на наш взгляд, становится осознанной необходимостью для будущих специалистов, стремящихся достичь успеха в жизни с помощью профессиональных знаний и навыков [2-4].

В связи с этим данный вопрос приобретает актуальность и дает нам возможность провести мониторинг сформированности культуры делового общении у сту- дентов неязыкового вуза. Данный процесс рассматривается нами как апробация нашего исследования в подготовке специалистов, востребованных на рынке труда, и способных составить конкуренцию при приеме на работу.

В качестве респондентов мы взяли студентов аграрного (неязыкового) вуза и провели мониторинг с помощью комплекса общеизвестных методов психологопедагогического исследования (опрос, тестирование, наблюдение, эксперимент) [1].

Нами был разработан опросный лист, с помощью которого мы провели опрос среди студентов, на предмет знаний о культуре делового общения. В опросном листе респондентам предлагался вопрос «Можете ли вы?...» и 11 позиций, на которые обследуемые должны были дать утверждение («да, могу» или «нет, не могу). Студенты отвечали на следующие позиции поставленного вопроса «Можете ли вы?...»:

- изъясняться правильным языком, соответствующим общепринятым языковым нормам;

- принимать во внимание сферы общения («студент-студент», «студент-преподаватель», студенческая научная конференция и т.д.);

- конкретно формулировать свои предложения, делая доступной для всех их конструктивность, 
новизну;

- изъясняться понятным, красочным языком;

- уметь выслушать оппонента;

- доказательно и четко выражать свои мысли;

- быть сдержанным в жестах;

- уважать мнение оппонента;

- удерживать внимание слушателя, не злоупотреблять паузами в речи;

- использовать эмоциональные средства воздействия;

- избегать однообразия в речи [8].

Результаты опроса студентов представлены в рис.1.

Анализ опроса показал, что 30\% студентов положительно ответили на позиции № 1 и 8 ; - 25\% опрошенных на позицию № 2; - 35\% на позицию № 3; - 3\% на позицию № 4; - 20\% на позицию № 5; - 5\% на позицию № 6; - $10 \%$ на позицию № 7; - 1\% на позицию № 9; - 15\% на позицию № 11. И, к сожалению, 100\% респондентов отрицательно ответили на позицию № 10.

Опрос показал низкий уровень сформированности культуры делового общения у студентов, несмотря на то что дисциплина «Культура речи и деловое общение» является частью их профессиональной подготовки в вузе.

Метод опроса, как единичный метод, не может дать достоверные результаты. Для достоверных результатов необходим комплекс методов психолого-педагогического исследования. В связи с этим мы провели тестирование, главной целью которого было выявить у респондентов имеющиеся у них базовые знания о содержании культуры делового общения.

Разработанные нами тестовые задания состояли из 45 вопросов, направленных на раскрытие содержания культуры делового общения. Результаты анализа тестовых заданий у студентов представлены в рис. 2.

Анализ результатов тестирования показал, что 13\% студентов правильно ответили на позицию № $1 ;-20 \%$ на позиции № 2 и 3; - 10\% на позиции № 4, 7 и 10; - 30\% на позиции № 5 и 8; - 5\% на позицию № 6; - 7\% на позицию № 9; - 25\% на позицию № 11.

Таким образом, тестирование студентов на содержание культуры делового общения показало результат несколько лучше, но не настолько, чтобы повысить сформированность культуры делового общения студентов.

Получив и обработав результаты опроса и тестирования, мы сочли необходимым провести наблюдения за студентами в два этапа.

Целью первого этапа наблюдения было выявление

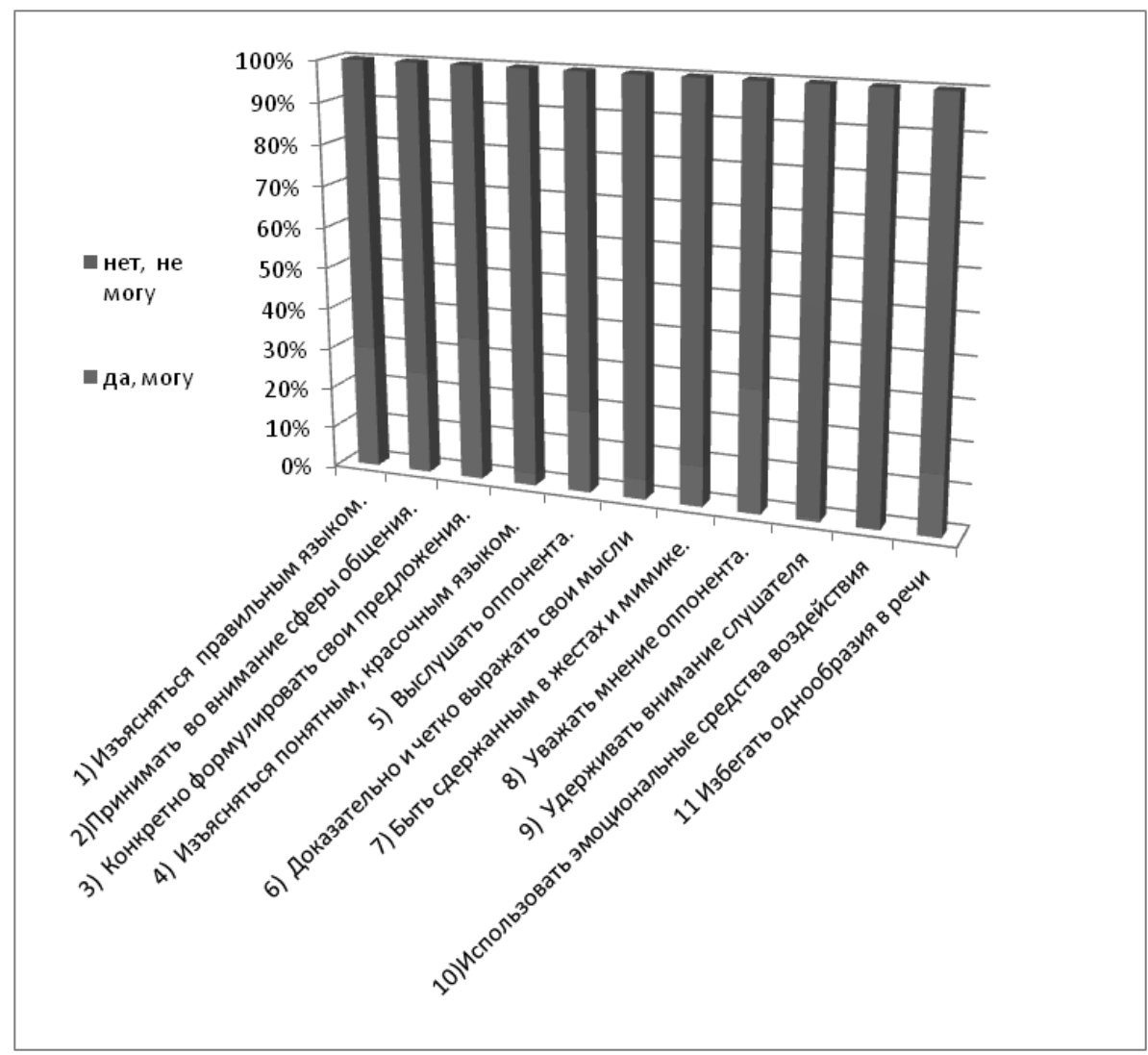

Рис. 1. Результаты опроса студентов на предмет знания культуры делового общения 


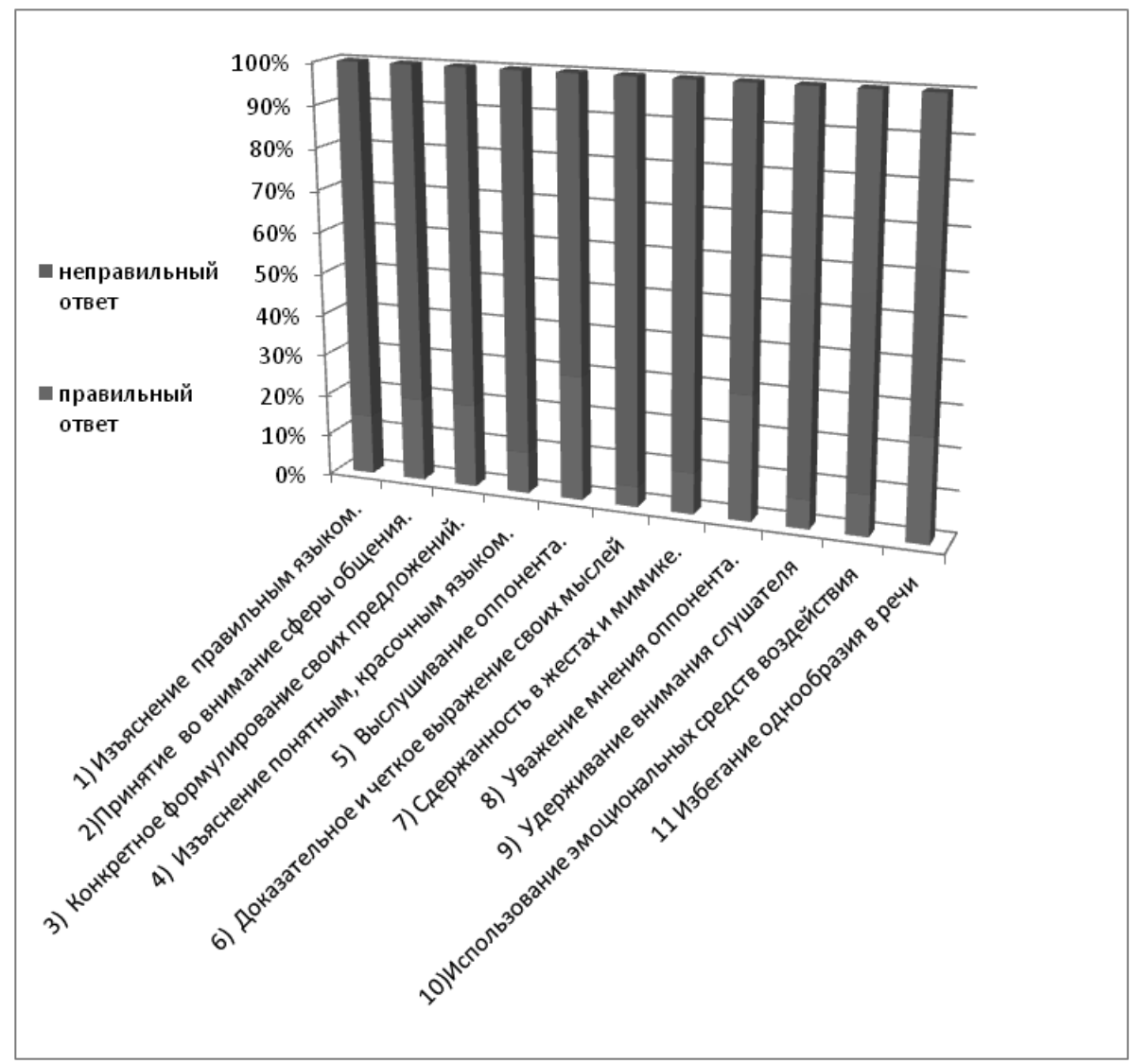

Рис. 2. Результаты тестирования студентов на предмет знания содержания культуры делового общения

у студентов специфики делового общения в учебной деятельности. Учитывались их ответы на занятиях, общение в микро группах при совместной подготовке к ответу, общение между студентами и преподавателями в процессе учебной деятельности. Нами проводился анализ следующих позиций специфики делового общения:

- словарный запас (яркость речи и способность человека внятно и красиво донести свои мысли, убедить в значимости своих идей);

- состав речи (разговаривать на чистом языке, уместно употреблять профессиональные термины);

- грамотность (фразы и предложения составлены с учетом стилистических и грамматических правил языка);

- произношение и интонация (важно не только, что говорит человек, но и как он говорит);

- невербальные составляющие (мимика, жесты, поза говорящего играют значимую роль в культуре делового общения) [8].

Результаты позиций специфики делового общения на первом этапе наблюдения мы отразили в рис. 3.

Результаты первого этапа наблюдения показали, что 30\% студентов правильно применяют специфику № 1; 15\% специфику № 2; - 10\% специфику № 3; - 7\% специфи- ку № 4; - 5\% специфику № 5.

Целью второго этапа наблюдения было выявление у студентов специфики делового общения в конкретно поставленных проблемных ситуациях.

На втором этапе наблюдения мы разделили респондентов на 8 мини групп, где каждая мини группа получила, разработанные нами задания по культуре делового общения. Каждая мини группа была включена в разрешение всех проблемных ситуаций, т.к. происходил обмен ситуациями после их разрешения. Содержание проблемных ситуаций отражено в (табл.1).

Результаты специфики делового общения студентов на втором этапе наблюдения отражены в рис. 4.

Результаты второго этапа наблюдения показали, что 15\% студентов правильно применяют специфику делового общения в ситуациях № 1, 6 и 8; - 25\% ситуации № 2 и 4; - 20\% в ситуации № 3; - 25\% в ситуации № 4; - $10 \%$ в ситуации № 5; - 35\% в ситуации № 7.

Таким образом, опрос, тестирование и наблюдение показали, что сформированность культуры делового общения у студентов находится на недостаточно высоком уровне. Им необходимы дополнительные теоретические знания и практические умения в данной области 


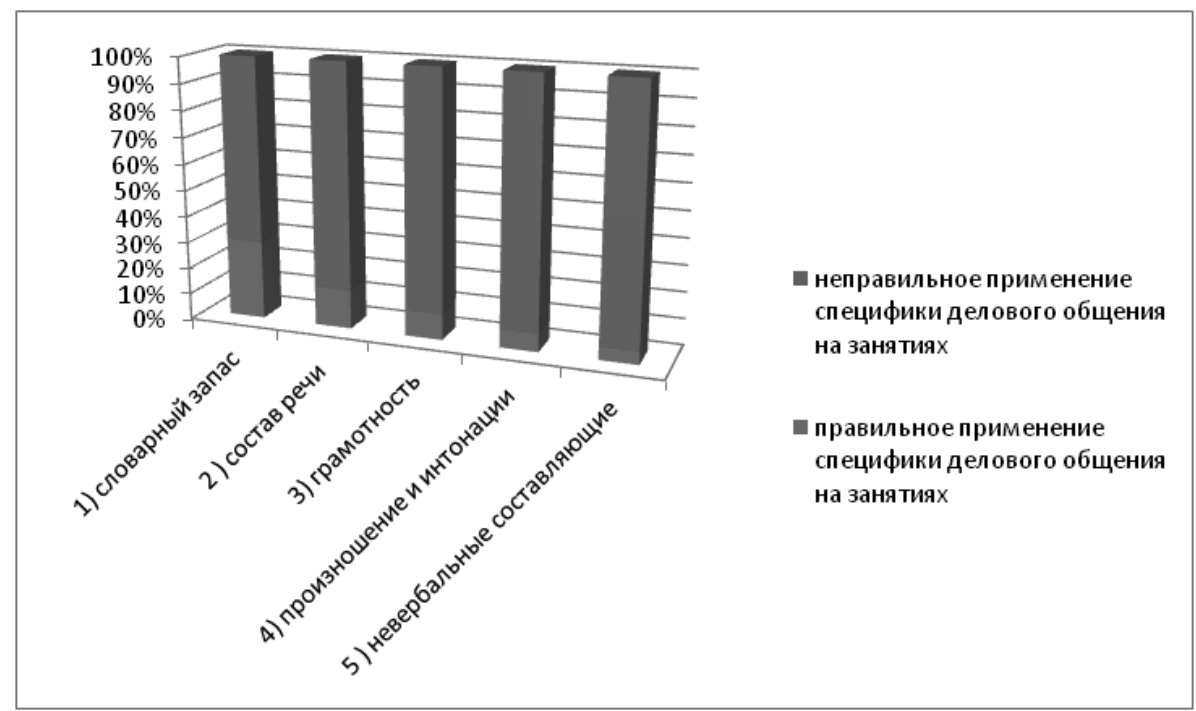

Рис. 3. Результаты позиций специфики делового общения студентов на первом этапе

Таблица 1.

Проблемные ситуации по культуре делового общения

1 Поведение человека, делающего все вовремя (пунктуальность), является нормативным в культуре делового общения. Вы опоздали на занятие или не в срок выполнили работу. Как это отразится на вашей учебной деятельности? Как вы будете изъясняться с преподавателем, применив навыки культуры делового общения.

2 Секреты (конфиденциальность) учреждения, корпорации необходимо хранить так же бережно, как тайны личного характера. Используя навыки культуры делового общения, объясните оппоненту, что вы не намерены раскрывать данный вопрос.

3 Любезность, доброжелательность и приветливость также являются нормативными в культуре делового общения. Вас вывел из терпения ваш сокурсник. Как вы поступите, используя навыки культуры делового общения?

4 Внимание к окружающим (думайте о других, а не только о себе). Используя навыки культуры делового общения, укажите на кого должно распространяться внимание и каким образом?

5 Уважение к мнению других. Используя навыки культуры делового общения, постарайтесь понять, почему у вашего оппонента сложилась та или иная точка зрения? Опишите данный процесс.

6 Прислушивайтесь к критике и советам. Вас подвергли критике. Используя навыки культуры делового общения, опишите ваши действия.

7 Внешний облик (одевайтесь, как положено). Опишите, какой внешний вид должен быть у вас, чтобы вписаться в окружение работников вашего уровня или студенческой среды.

8 Грамотность (говорите и пишите хорошим языком). Используя навыки культуры делового общения, попробуйте написать деловое письмо вашему сокурснику. В письме должно быть не менее 5-ти строк.

деятельности. Формирование же культуры делового общения, на наш взгляд, поможет студенту овладеть мастерством в области профессиональной деятельности и тем самым составить востребованность и конкуренцию на рынке труда.

Однако следует отметить, что формирование культуры делового общения - процесс сложный и длительный. Анализ результатов исследования показал, что формирование культуры делового общения у студентов имеет свои специфические задачи, решение которых следует разделить во времени. Это обусловило необходимость разработки и внедрения в педагогический процесс неязыкового вуза, адаптированной методики формирования культуры делового общения в профессиональной сфере.

На стадии эксперимента нами был разработан и точечно внедрен в педагогический процесс спецкурс «Культура делового общения в профессиональной сфере», включающий в себя не только теоретический материал и практические занятия, но и тренинги и деловые 


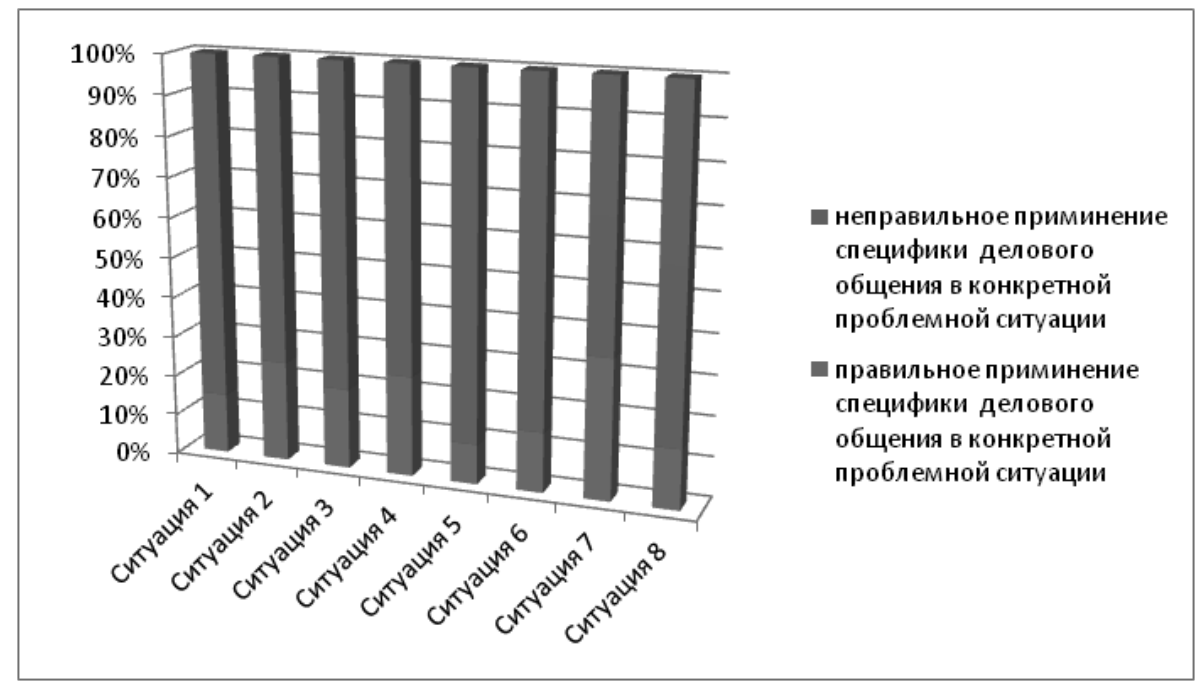

Рис. 4. Результаты специфики делового общения студентов на втором этапе наблюдения

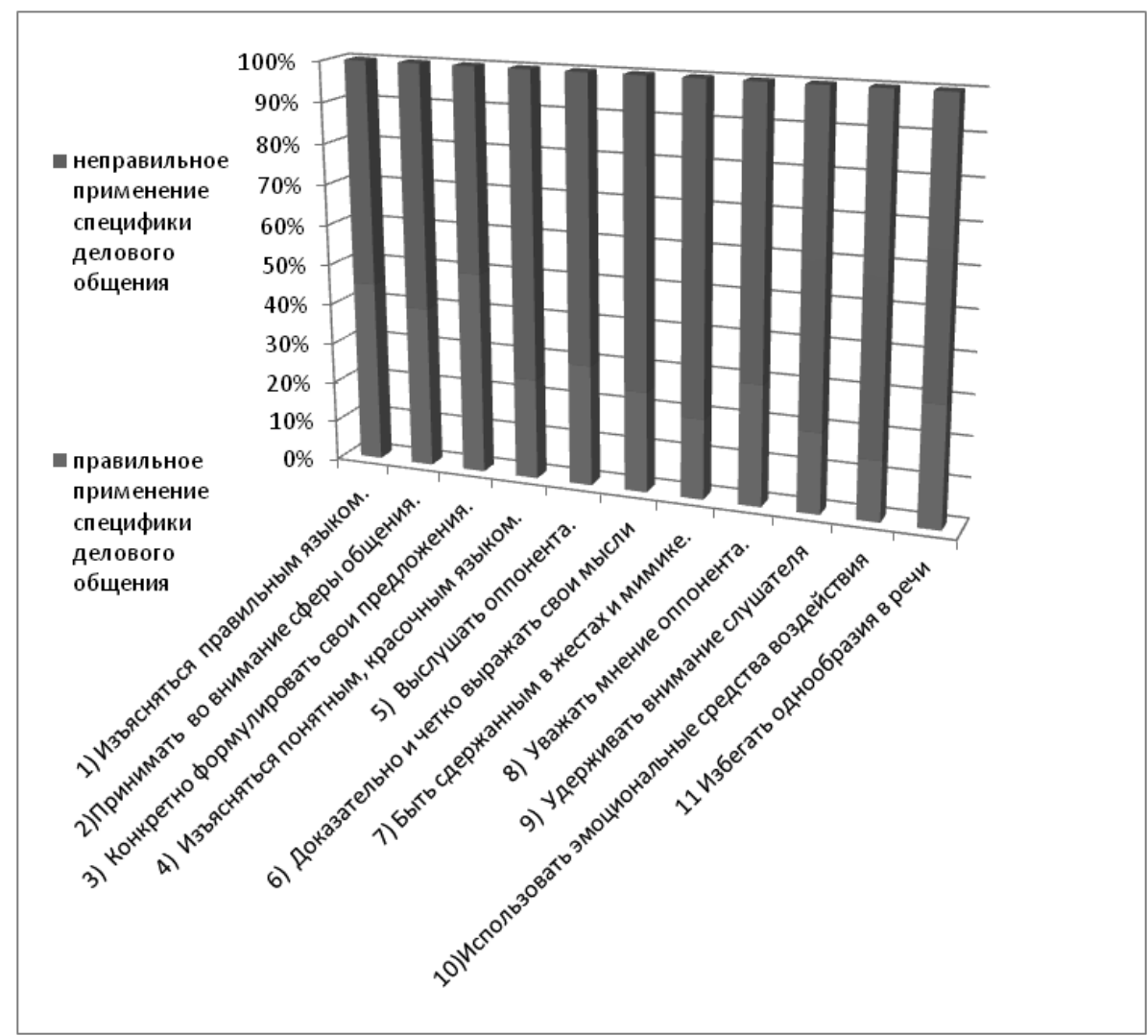

Рис. 5. Результаты контрольного «среза» студентов на предмет применения специфики делового общения

игры. По окончании данного эксперимента студенты снова прошли опрос, тестирование и разрешение конкретных проблемных ситуаций. Применив математический метод обработки результатов, мы получили контрольный «срез», результаты которого представлены в рис. 5.

Сравнение результатов опроса, тестирования и наблюдения дает возможность наблюдать положительную динамику в формировании культуры делового общения у студентов неязыкового аграрного вуза [6, 7].

Таким образом, наше исследование показало, что студенты получили определенные знания и практические умения по культуре делового общения и успешно используют их в подготовке к профессиональной деятельности. Следовательно, разработанная и внедренная нами в педагогический процесс неязыкового вуза методика формирования культуры делового общения в профессиональной сфере показала свою эффективность. 


\section{ЛИТЕРАТУРА}

1. Агафонова И.Н. Психология делового общения: Учебно-методическое пособие по курсу «Социальная психология». СПб., 2009. 150 с.

2. Богданова Ю.З. Инновационные методы преподавания русского языка и культуры речи в неязыковом вузе // Перспективы науки. 2019. № 3 (114). C. 68-71.

3. Богданова Ю.3. 06 изменении традиций воспитательной работы в вузе // Гуманитарные и социальные науки. 2018. № 6. С. 321-329.

4. Богданова Ю.З. Риторика как важная составляющая профессиональной подготовки студентов // Мир науки, культуры, образования. 2018. № 5 (72). C. 413-414.

5. Игнатенко И.И. Формирование культуры иноязычного делового общения студентов в системе высшего гуманитарного образования: учеб. пособие. М.: Изд-во МПГУ, 2018. 200 c.

6. Касумова Г.А. Использование риторических технологий ля формирования коммуникативной компетенции у студентов аграрного университета // Проблемы современного педагогического образования. 2020. № 69-3. С. 94-97.

7. Касумова Г.А., Моложавенко В.Л. Учебный диалог как коммуникативная составляющая речевой культуры // Инновации. Наука. Образование. 2020. № 12. C. 582-588.

8. Поскочинова О.Г., Гриднева М.А. Культура речи и деловое общение: учеб. пособие. СПб.: Изд-во СПбГУЭФ, 2011.95 с.

9. Федеральные государственные образовательные стандарты высшего образования (ФГОС ВО) нового поколения от 18 ноября 2013 г. N 1245 с изменениями, внесенными приказом Минобрнауки РФ от 29 июня 2015 г. N 633.

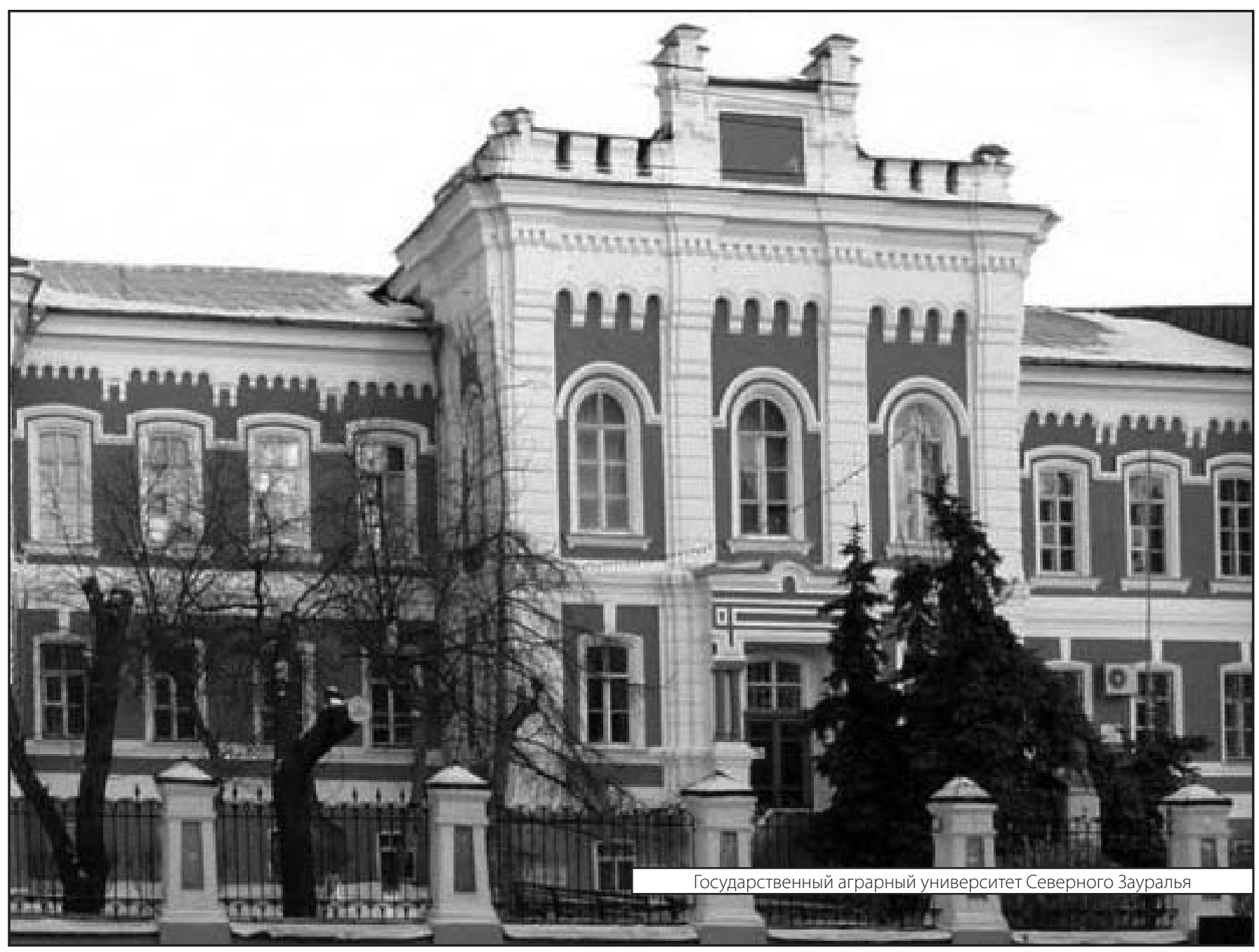

